\title{
Erythroderma due to iatrogenic immunosuppression: A case of Norwegian scabies
}

\author{
Mohammad Adil', Syed Suhail Amin'1, Mohd Mohtashim', Sabha Mushtaq', \\ Shagufta Qadri ${ }^{2}$, Iti Varshney ${ }^{1}$
}

1Department of Dermatology, Jawaharlal Nehru Medical College (JNMC), Aligarh Muslim University (AMU), Aligarh, India. ${ }^{2}$ Department of Pathology, Jawaharlal Nehru Medical College (JNMC), Aligarh Muslim University (AMU), Aligarh, India.

Corresponding author: Dr. Mohammad Adil, E-mail: dr.mohd.adil@gmail.com

\begin{abstract}
Norwegian scabies is a rare type of scabies characterised by hyperkeratotic and crusted plaques and is usually seen in immunologically and neurologically impaired patients. An elderly female presented to us with erythema and scaling over the body along with thick plaques covered with yellow crusts over the flexor aspects of the wrists and forearm. There was family history suggestive of scabies in other family members. The patient had received multiple injections of triamcinolone and was applying topical ointment containing steroids for tinea corporis. The HIV ELISA was non reactive. A potassium hydroxide mount showed multiple mites, eggs and faecal pellets. A diagnosis of Norwegian scabies was made and patient treated with oral ivermectin and topical permethrin. We present this case to highlight the possibility of this rare cause of erythroderma in a patient who has been receiving corticosteroids.
\end{abstract}

Key words: Scabies, Erythroderma, Parasitic disease

\section{INTRODUCTION}

Erythroderma, defined as erythema and scaling over more than $90 \%$ body surface area is usually the result of eczematous group of diseases (40\%), psoriasis (15\%), drugs $(10 \%)$ and malignancies $(15 \%)$ in elderly patients. Rarely, it may result from other conditions such as pemphigus foliaceous $(0.5 \%)$ dermatomyositis, scabies and lichen planus $(0.5 \%)$ [1]. Scabies, an ectoparasitic infestation, is a common disease and can present in various forms. A very rare but highly contagious form is the Norwegian scabies, where the host immune response in modified. The unhindered multiplication of the mite on the skin occurs as a result of absence of pruritus [2]. Norwegian scabies presents as thick crusted and hyperkeratotic plaques and rarely may lead to generalised involvement leading to erythroderma [3]. Herein, we describe a patient of Norwegian scabies occurring after long duration systemic and topical steroid therapy and presenting as erythroderma.

\section{CASE REPORT}

A 60 year old female presented to us with complaints of red raised itchy lesions over body since 6 months and generalised redness, scaling and crusting over body since 20 days. She gave history of receiving multiple injections of Triamcinolone in the last five years as well as application of an ointment containing clobetasol, gentamicin and miconazole for itchy annular skin lesions in axillae and groins (possibly Tinea cruris and corporis), prescribed to her by a quack. All members of her family had itchy lesions, predominantly present over the webs of fingers, genitalia, axillae and abdomen suggestive of scabies. On examination, she was found to have generalised erythema and scaling over most of her body (Fig. 1) including the face (Fig. 2) but sparing the palms and soles. There were ill defined plaques with thick, yellow, hyperkeratotic crusts with deep fissures present over the flexor aspect of wrists, forearms, cubital fossa (Fig. 3) and upper medial aspect of

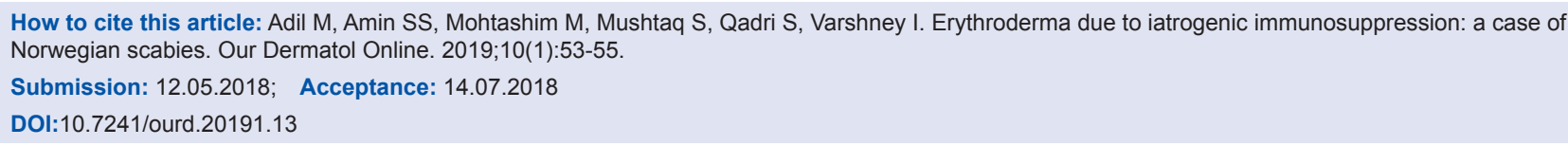


thighs. Excoriated papules surmounted by crusts were also seen over the trunk and extremities. Examination of nails, hair, mucosa showed no abnormality. The

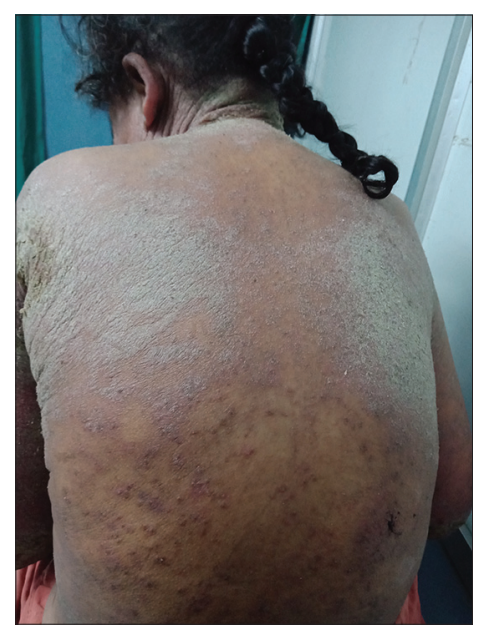

Figure 1: Erythema and scaling and few excoriated papules over the back.

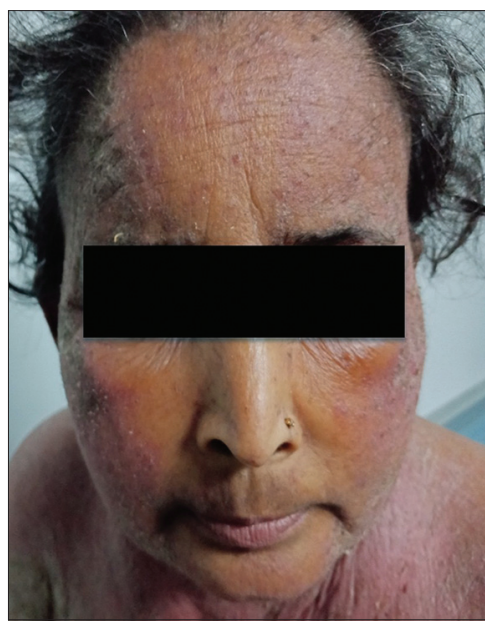

Figure 2: Erythema and scaling over the face

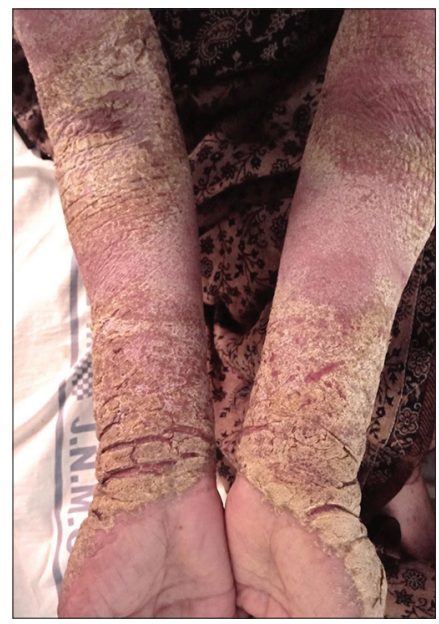

Figure 3: Crusted plaques over the flexor aspect of wist, forearm and cubital fossae systemic examination was normal with no evidence of any neurological deficit.

A potassium hydroxide mount revealed the presence of numerous scabies mite, eggs and scybala (Fig. 4). Routine investigations including blood counts and serum biochemistry was within normal limits, except for anaemia (Hb-8.8mg\%). HIV ELISA was non-reactive. The chest radiograph, ultrasonography of abdomen and pelvis was normal. Skin biopsy from a papule over the back showed an intra-corneal vesicle with scabies mite and its faecal matter. There was polymorphonuclear infiltrate in the dermis (Fig. 5). Based on the clinical picture, $\mathrm{KOH}$ mount and histopathology, a diagnosis of erythroderma due to Norwegian scabies resulting from immunosuppression of systemic steroid abuse was made. The patient was admitted in isolation ward and treated with weekly Ivermectin $18 \mathrm{mg}$ and topical permethrin $5 \%$ cream with all her family members. She

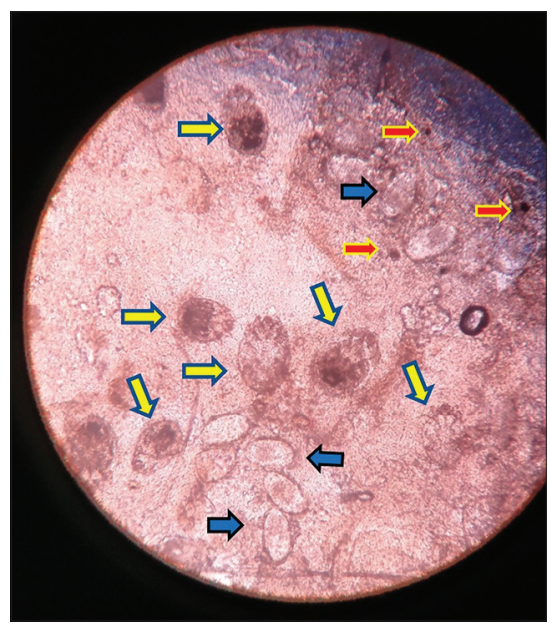

Figure 4: Potassium hydroxide mount showing multiple scabies mites (yellow arrows), eggs (blue arrows) and scybala (red arrows)

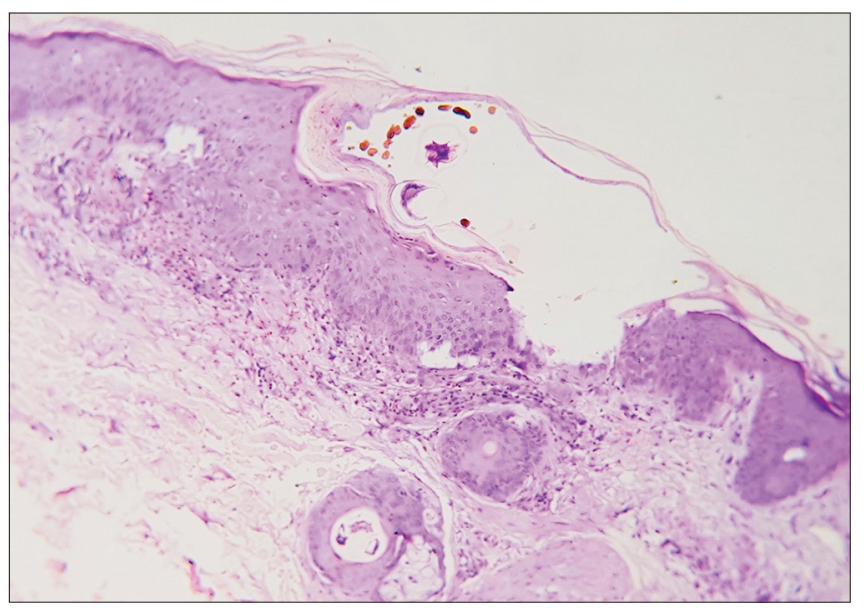

Figure 5: Histopathology of the papule shows intra-corneal vesicle containing scabies mite, faecal pellets and infiltrate in the dermis. 
responded very well to treatment and $\mathrm{KOH}$ mount was negative for mites after 15 days.

Prior to the study, patient gave written consent to the examination and biopsy after having been informed about the procedure.

\section{DISCUSSION}

Crusted scabies is a rare manifestation of infestation by Sarcoptes scabei mite which was first described in leprosy patients in Norway, hence the name Norwegian scabies. Crusted scabies is seen in immunosuppressed and mentally debilitated or neurologically impaired patients. While the number of mites in a patient of classical scabies is usually in the range of 10-20, millions of mites are present in a patient of Norwegian scabies, which is attributed to the lack of hypersensitivity and no itching seen in such patients. An altered immunity is responsible for the excessive multiplication of mites in immunosuppressed patients. Itching is a protective response that destroys the burrows and keeps the population of mites in check. Itching is a result of hypersensitivity and is thus less prominent in patients with immune deficiency. Also neurologically impaired patients do not perceive itch and are predisposed to itching [4].There have been very few reports of crusted scabies in patients receiving immunosuppressive drugs including systemic and topical steroids [5-7]. The disease may present as crusted plaques, psoriasiform lesions or as erythroderma $[4,8]$.The diagnosis requires a high index of suspicion. A simple potassium hydroxide mount of the skin scrapping reveals numerous mites in various stages of development, eggs and scabala, the faecal pellets of the mite [9]. Treatment is challenging due to the heavy load of mites on the body as well as the presence of thick plaques. Treatment consists of the application of keratolytic agents to diminish the hyperkeratotic plaques and requires repeated oral ivermectin administration with multiple applications of topical scabicidal agents such as permethrin $5 \%$ [10].
We present a rare case of erythroderma due to Norwegian scabies resulting from immunosuppression due to systemic and topical steroids. This case is being presented to highlight the need to consider the possibility of this rare disease entity, particularly in patients who have received long term steroids.

\section{CONSENT}

The examination of the patient was conducted according to the Declaration of Helsinki principles.

\section{REFERENCES}

1. Das A, Bar C, Patra A. Norwegian scabies Rare cause of erythroderma. Indian Dermatol Online J. 2015;6:52-4.

2. Ebrahim KC, Alves JB, Tomé LA, Moraes CF, Gaspar AD, Franck KF, et al. Norwegian scabies - rare case of atypical manifestation An Bras Dermatol. 2016;91:826-8.

3. Burns DA. Diseases caused by arthropods and other noxious animals. In: Burns T, Breathnach S, Cox N, Griffiths C, editors. Rook's Textbook of Dermatology. $8^{\text {th }}$ ed. Oxford: WileyBlackwell; 2010. pp. 38.40-14.

4. Chang P, Quijada Ucelo ZM. [Norwegian scabies in an immunocompromised patient]. Our Dermatol Online. 2017;8:484-6.

5. Binic I, Jancovic A, Jovanovic D, Ljubenovic M. Crusted scabies following systemic and topical corticosteroid therapy. J Korean Med Sci. 2010;25:188-91.

6. Lima FCR, Cerqueira AMM, Guimarães MBS, Padilha CBS, Craide FH, Bombardelli M. Crusted scabies due to indiscriminate use of glucocorticoid therapy in infant. An Bras Dermatol. 2017;92:383-5.

7. Sivasubramanian G, Siddiqui MF, Tangella KR. Scabies crusts following corticosteroid therapy in an elderly patient. Am J Med Sci 2012;343:248-9.

8. Anbar TS, Raouf HA, Shalaby S, Abdel-Rahman AT, Ahmed SS. Erythroderma, Scaly Scalp and Nail Dystrophy: A Misleading Association. J Clin Exp Dermatol Res. 2014;5:219.

9. Kamath MV, Gupta RA, Nadkarni N, Sonavane S. Scrape or Perish: The importance of skin scraping in erythroderma. Indian Dermatol Online J. 2011;2:107-8.

10. Costa JB, Rocha de Sousa VL, da Trindade Neto PB, Paulo Filho Tde A, Cabral VC, Pinheiro PM. Norwegian scabies mimicking rupioid psoriasis. An Bras Dermatol. 2012;87:910-3.

Copyright by Mohammad Adil, et al. This is an open-access article distributed under the terms of the Creative Commons Attribution License, which permits unrestricted use, distribution, and reproduction in any medium, provided the original author and source are credited.

Source of Support: Nil, Conflict of Interest: None declared. 